\title{
Time-Resolved Synchrotron X-Ray Powder Diffraction Study on Samples from the System $\mathrm{MgO}-\mathrm{MgCl}_{2}-\mathrm{H}_{2} \mathrm{O}$
}

\author{
A. Nørlund Christensen, ${ }^{\dagger, a}$ P. Norby ${ }^{b}$ and J. C. Hanson ${ }^{b}$ \\ ${ }^{a}$ Department of Inorganic Chemistry, Aarhus University, DK-8000 Aarhus C, Denmark and ${ }^{\mathrm{b}}$ Chemistry Department, Brookhaven \\ National Laboratory, Upton, New York 11973, USA
}

\begin{abstract}
Christensen, A. N., Norby, P. and Hanson, J. C., 1995. Time-Resolved Synchrotron X-Ray Powder Diffraction Study on Samples from the System MgO$\mathrm{MgCl}_{2}-\mathrm{H}_{2} \mathrm{O}$. - Acta Chem. Scand. 49: 331-334 @ Acta Chemica Scandinavica 1995 .

Time-resolved synchrotron $\mathrm{X}$-ray powder diffraction was used to study chemical reactions in the system $\mathrm{MgO}-\mathrm{MgCl}_{2}-\mathrm{H}_{2} \mathrm{O}$ at temperatures up to $100^{\circ} \mathrm{C}$. The crystalline reaction products formed were $\mathrm{Mg}(\mathrm{OH})_{2}, \mathrm{MgCl}_{2} \cdot 5 \mathrm{Mg}(\mathrm{OH})_{2} \cdot 8 \mathrm{H}_{2} \mathrm{O}$, $\mathrm{MgCl}_{2} \cdot 9 \mathrm{Mg}(\mathrm{OH})_{2} \cdot 5 \mathrm{H}_{2} \mathrm{O}$ and $\mathrm{MgCl}_{2} \cdot 2 \mathrm{Mg}(\mathrm{OH})_{2} \cdot 4 \mathrm{H}_{2} \mathrm{O}$. The reaction rates are strongly dependent upon the temperature and slightly dependent on the concentration of the magnesium chloride solutions.
\end{abstract}

In a recent investigation, chemical reactions in the system $\mathrm{MgO}-\mathrm{MgCl}_{2}-\mathrm{H}_{2} \mathrm{O}$ were studied by on-line synchrotron $\mathrm{X}$-ray powder diffraction at temperatures up to $100^{\circ} \mathrm{C}$. $^{1}$ The crystalline reaction products formed were $\mathrm{Mg}(\mathrm{OH})_{2}$ and $\mathrm{MgCl}_{2} \cdot 5 \mathrm{Mg}(\mathrm{OH})_{2} \cdot 8 \mathrm{H}_{2} \mathrm{O}$, when the concentrations of the magnesium chloride solutions were in the range from 0 to $4 \mathrm{M}$. In this work, the system is further investigated with magnesium chloride solutions in the range from 3.8 to $4.9 \mathrm{M}$.

The solid magnesium chloride hydroxide hydrates formed in the system $\mathrm{MgO}-\mathrm{MgCl}_{2}-\mathrm{H}_{2} \mathrm{O}$ are components in Sorel's cement. ${ }^{2}$ The system was investigated at hydrothermal conditions at temperatures up to $175^{\circ} \mathrm{C}$ by Bianco, ${ }^{3}$ and the crystalline magnesium chloride hydroxide hydrates identified by Bianco are listed in Table 1 . The short notation for the compounds will be used below.

Table 1. Composition of magnesium chloride hydroxide hydrates, notation as in Ref. 3.

\begin{tabular}{lllr}
\hline Compound & $\begin{array}{l}\text { Short } \\
\text { notation }^{a}\end{array}$ & JCPDS card No. \\
\hline $\mathrm{MgCl}_{2} \cdot 5 \mathrm{Mg}(\mathrm{OH})_{2} \cdot 8 \mathrm{H}_{2} \mathrm{O}$ & $\mathrm{Cl}_{5,8}$ & $12-122,7-420$ \\
$\mathrm{MgCl}_{2} \cdot 3 \mathrm{Mg}(\mathrm{OH})_{2} \cdot 8 \mathrm{H}_{2} \mathrm{O}$ & $\mathrm{Cl}_{3,8}$ & $7-412,36-388$ \\
$\mathrm{MgCl}_{2} \cdot 9 \mathrm{Mg}(\mathrm{OH})_{2} \cdot 5 \mathrm{H}_{2} \mathrm{O}$ & $\mathrm{Cl}_{9,5}$ & $12-123,7-409$ \\
$\mathrm{MgCl}_{2} \cdot 2 \mathrm{Mg}(\mathrm{OH})_{2} \cdot 4 \mathrm{H}_{2} \mathrm{O}$ & $\mathrm{Cl}_{2,4}$ & $12-116$ & \\
$\mathrm{MgCl}_{2} \cdot 2 \mathrm{Mg}(\mathrm{OH})_{2} \cdot 2 \mathrm{H}_{2} \mathrm{O}$ & $\mathrm{Cl}_{2,2}$ & $12-133$ \\
\hline
\end{tabular}

${ }^{a}$ As only the composition was known by Bianco, ${ }^{3}$ it was given as $\mathrm{MgCl}_{2} \cdot p \mathrm{Mg}(\mathrm{OH})_{2} \cdot q \mathrm{H}_{2} \mathrm{O}$, and the short notation as $\mathrm{Cl}_{p, q}$.

\footnotetext{
$\uparrow_{\text {To whom }}$ correspondence should be addressed.
}

The heterogeneous system $\mathrm{MgO}-\mathrm{MgCl}_{2}-\mathrm{H}_{2} \mathrm{O}$, where the reactant, the crystalline $\mathrm{MgO}$, is consumed, and where crystalline reaction products are formed in time, is ideal for time-resolved diffraction experiments. The reactions are rather slow at room temperature and relatively fast at $100^{\circ} \mathrm{C}$.

\section{Experimental}

The chemicals used in the investigation were basic magnesium carbonate (Merck p.a.) and magnesium chloride hexahydrate, $\mathrm{MgCl}_{2} \cdot 6 \mathrm{H}_{2} \mathrm{O}$ (Merck p.a.). The basic magnesium carbonate was identified from its X-ray powder patterns as magnesium carbonate hydroxide hydrate, $\mathrm{Mg}_{5}\left(\mathrm{CO}_{3}\right)_{4}(\mathrm{OH})_{2} \cdot 4 \mathrm{H}_{2} \mathrm{O}$, hydromagnesite (JCPDS index card No. 25-513). Differential thermal analysis and thermogravimetric analysis were made of the basic magnesium carbonate on a Stanton Redcroft TG-DTA simultaneous thermal analyser STA $1000 / 1500$. A sharp endothermic peak at $537^{\circ} \mathrm{C}$ corresponds to the formation of $\mathrm{MgO}$, and a total weight loss of $57 \%$ was in good agreement with the chemical formula for hydromagnesite. In the preparation of a batch of $\mathrm{MgO}$ the basic magnesium carbonate was kept in a crucible of $\mathrm{Al}_{2} \mathrm{O}_{3}$ at $700^{\circ} \mathrm{C}$ for $12 \mathrm{~h}$, and $\mathrm{MgO}$ so obtained was stored in an air-tight plastic bottle.

A preliminary investigation of the system $\mathrm{MgO}-$ $\mathrm{MgCl}_{2}-\mathrm{H}_{2} \mathrm{O}$ was made at hydrothermal conditions at $125^{\circ} \mathrm{C}$ to determine conditions for formation of $\mathrm{Mg}(\mathrm{OH})_{2}$ and the magnesium chloride hydroxide hydrates. The reaction products were identified from their X-ray powder patterns, and Fig. 1 displays the results obtained at 




Fig. 1. Investigation of the system $\mathrm{MgO}-\mathrm{MgCl}_{2}-\mathrm{H}_{2} \mathrm{O}$ at $125^{\circ} \mathrm{C}: \mathrm{Mg}(\mathrm{OH})_{2}(\mathrm{O}), \mathrm{Cl}_{5,8}(\square), \mathrm{Cl}_{3,8}(\nabla)$ and $\mathrm{Cl}_{9,5}(\nabla)$. The composition of the reaction product depends upon the concentration of the $\mathrm{MgCl}_{2}$ solutions and the molar ratio $\mathrm{MgCl}_{2} / \mathrm{MgO}$.

$125^{\circ} \mathrm{C}$. In the on-line diffraction experiments the samples used were wet pastes made from $50 \mathrm{mg} \mathrm{MgO}$ and 20 drops of the magnesium chloride solutions. The paste was housed in a $0.3 \mathrm{~mm}$ diameter quartz capillary. The samples were prepared as described previously ${ }^{1}$ and were placed on the diffractometer and heated with a flow of hot, compressed air.

Synchrotron X-ray powder patterns were measured at $1.0,2.5,5.0$ or 10.0 min intervals of the capillaries on a Huber diffractometer at the beam line X7B at NSLS, Brookhaven National Laboratory. A type CPS 120 curved INEL position-sensitive detector covering $120^{\circ}$ in $2 \theta$ was mounted on the $\theta$-arm of the diffractometer. The detector was calibrated as described previously, ${ }^{1}$ and the wavelength used, $\lambda=1.2097 \AA$, was determined in a profile refinement of a powder pattern of a silicon standard with $a=5.4305 \AA$.

In a real-time X-ray powder diffraction a rather large number of patterns are recorded for each sample. The patterns are plotted in a display which shows the evolution in time of the powder patterns (see below). Relative quantities of reactant or product can be measured by integration of selected Bragg reflections of the crystalline solids. The end products of the reactions were identified from the X-ray powder patterns of the last patterns in each series of measurements. The DIFFRAC AT program was used for plotting the powder patterns, and the program FIT was used to determine integrated intensities by profile fitting (Siemens D5000 software).

\section{Results and discussion}

In the preliminary hydrothermal investigation of the system $\mathrm{MgO}-\mathrm{MgCl}_{2}-\mathrm{H}_{2} \mathrm{O}$ at $125^{\circ} \mathrm{C}$, the reaction products formed were $\mathrm{Mg}(\mathrm{OH})_{2}, \mathrm{Cl}_{5,8}, \mathrm{Cl}_{3,8}$ and $\mathrm{Cl}_{9,5}$ (Fig. 1). For the formation of $\mathrm{Mg}(\mathrm{OH})_{2}$ this is in agreement with the results found in Ref. 1.

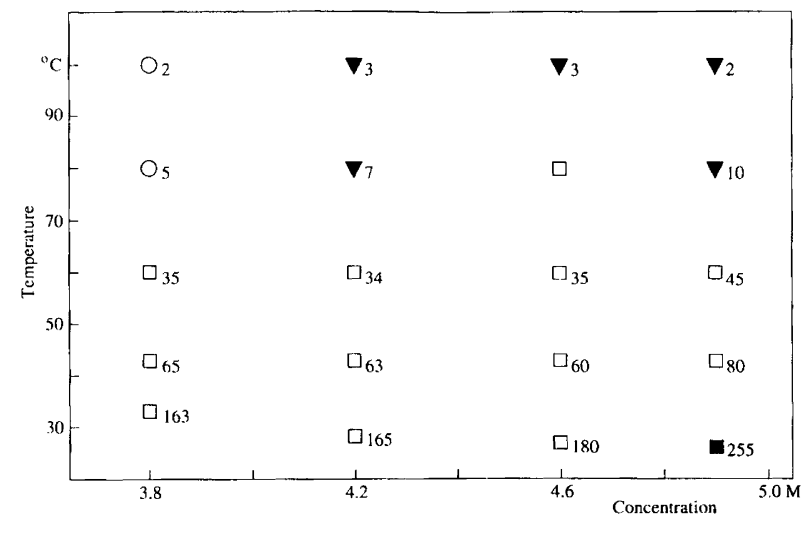

Fig. 2. Reaction products in the time-resolved diffraction investigation of the system $\mathrm{MgO}-\mathrm{MgCl}_{2}-\mathrm{H}_{2} \mathrm{O}: \mathrm{Mg}(\mathrm{OH})_{2}(\mathrm{O})$, $\mathrm{Cl}_{5,8}(\square), \mathrm{Cl}_{9,5}(\nabla)$ and $\mathrm{Cl}_{2,4}(\square)$. The numbers adjacent to the symbols indicate the time in min necessary to produce half the final quantity of the respective reaction products.

In all the time-resolved synchrotron $\mathrm{X}$-ray experiments $50 \mathrm{mg} \mathrm{MgO}$ and 20 drops of the magnesium chloride solutions were used, so the only parameters were the temperatures and the concentration of the solutions. The reaction products found in these experiments are shown in Fig. 2 and are the compounds $\mathrm{Mg}(\mathrm{OH})_{2}, \mathrm{Cl}_{5,8}, \mathrm{Cl}_{9,5}$ and $\mathrm{Cl}_{2,4}$, indicated by the four different symbols. Four solutions of $\mathrm{MgCl}_{2}$ were applied with the concentrations 3.8, $4.2,4.6$ and $4.9 \mathrm{M}$. With the $3.8 \mathrm{M}$ solution, $\mathrm{Mg}(\mathrm{OH})_{2}$ was obtained at 80 and $100^{\circ} \mathrm{C}$, and with the $4.2,4.6$ and 4.9 $\mathrm{M}$ solutions $\mathrm{Cl}_{9,5}$ was obtained at 80 and $100^{\circ} \mathrm{C}$. Only in one case, with the $4.9 \mathrm{M}$ solution at $26^{\circ} \mathrm{C}$, the magnesium chloride hydroxide hydrate $\mathrm{Cl}_{2,4}$ was obtained, and for the four solutions $\mathrm{Cl}_{5,8}$ was formed at temperatures up to $60^{\circ} \mathrm{C}$.

The rate of reactions in the heterogeneous systems can be visualized when the powder patterns of a series are plotted slightly shifted and in the same sequence as they have been recorded. In that way, it is possible to observe the decrease of Bragg reflections from the reactant $(\mathrm{MgO})$ and the increase of the intensities of the Bragg reflections



Fig. 3. X-Ray powder diffraction diagrams of a mixture of $\mathrm{MgO}$ and the $4.9 \mathrm{M} \mathrm{MgCl}_{2}$ solution at $80^{\circ} \mathrm{C}$ recorded at $2.5 \mathrm{~min}$ intervals. The reaction product is $\mathrm{Cl}_{9,5}$. 


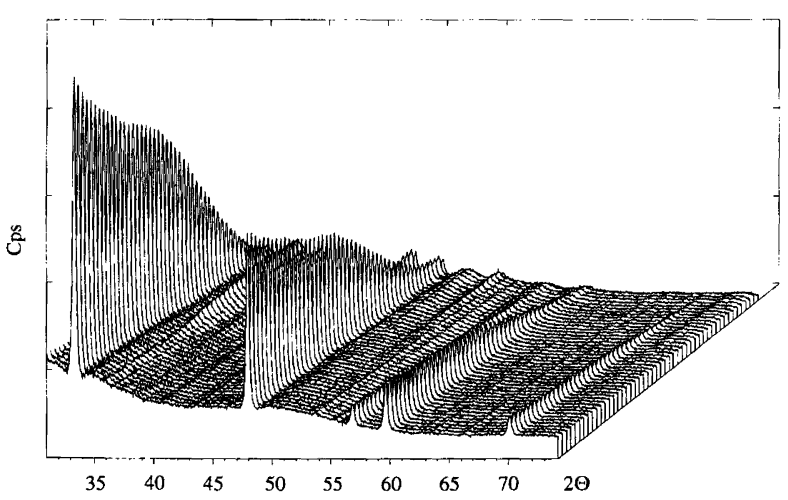

Fig. 4. X-Ray powder diffraction diagrams of a mixture of $\mathrm{MgO}$ and the $4.9 \mathrm{MgCl}_{2}$ solution at $26^{\circ} \mathrm{C}$ recorded at $10 \mathrm{~min}$ intervals. The reaction product is $\mathrm{Cl}_{2,4}$.

of the reaction products (the magnesium chloride hydroxide hydrates). Figure 3 shows such a display of a sample of $\mathrm{MgO}$ and the $4.9 \mathrm{M}$ solution of $\mathrm{MgCl}_{2}$ at $80^{\circ} \mathrm{C}$ where the powder patterns are recorded at $2.5 \mathrm{~min}$ intervals. It is obvious that the consumption of $\mathrm{MgO}$ as well as the production of $\mathrm{Cl}_{9,5}$ is relatively fast. Figure 4 displays the powder patterns from the reaction between $\mathrm{MgO}$ and the 4.9 $\mathrm{M}$ solution at $26^{\circ} \mathrm{C}$. The powder patterns are in this case recorded at $10 \mathrm{~min}$ intervals, and the consumption of $\mathrm{MgO}$ as well as the production of the product, $\mathrm{Cl}_{2,4}$, is slow.

A measure of the quantities of reactant and products is obtained from integration of selected Bragg reflections. Figures 5-8 display the results of such integrations for the reactions between $\mathrm{MgO}$ and the 3.8, 4.2, 4.6 and $4.9 \mathrm{M} \mathrm{MgCl}_{2}$ solutions, respectively, at the temperatures 60 and $45^{\circ} \mathrm{C}$, and room temperature $\left(33-26^{\circ} \mathrm{C}\right)$. The curves in Figs. 5-8 are drawn to guide the eye. In 11 of the 12 experiments the reaction product is $\mathrm{Cl}_{5,8}$, and only in the experiment with the $4.9 \mathrm{M}$ solution at $26^{\circ} \mathrm{C}$ is the reaction product $\mathrm{Cl}_{2,4}$ (Fig. 2). The rate of consumption of $\mathrm{MgO}$ is temperature dependent, but apparently only

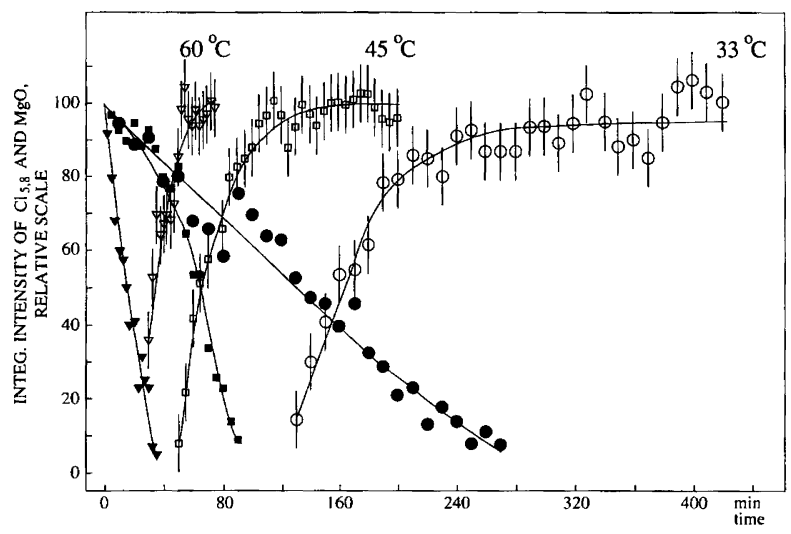

Fig. 5. Integrated intensities of Bragg reflections of $\mathrm{MgO}$ (filled symbols) and $\mathrm{Cl}_{5,8}$ (open symbols) vs. time for the reaction between $\mathrm{MgO}$ and the $3.8 \mathrm{M} \mathrm{MgCl}_{2}$ solution at 33 , 45 and $60^{\circ} \mathrm{C}$, respectively.

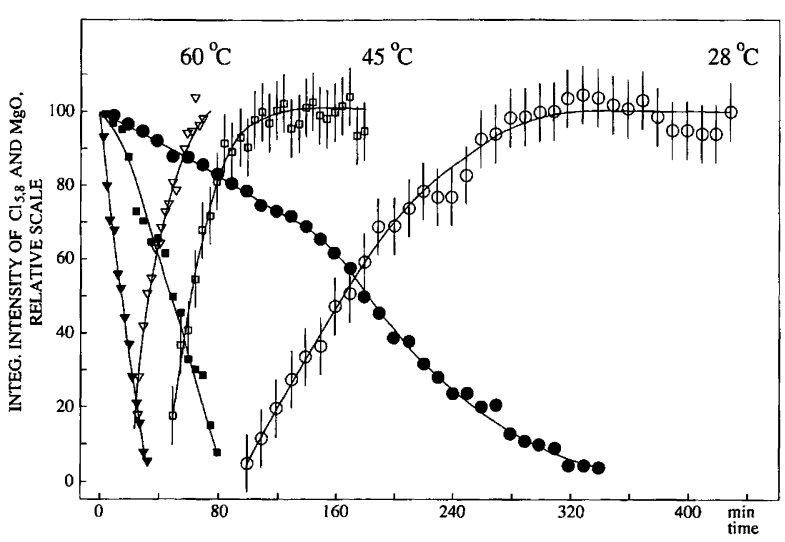

Fig. 6. Integrated intensities of Bragg reflections of $\mathrm{MgO}$ (filled symbols) and $\mathrm{Cl}_{5,8}$ (open symbols) vs. time for the reaction between $\mathrm{MgO}$ and the $4.2 \mathrm{M} \mathrm{MgCl}_{2}$ solution at 28 , 45 and $60^{\circ} \mathrm{C}$, respectively.

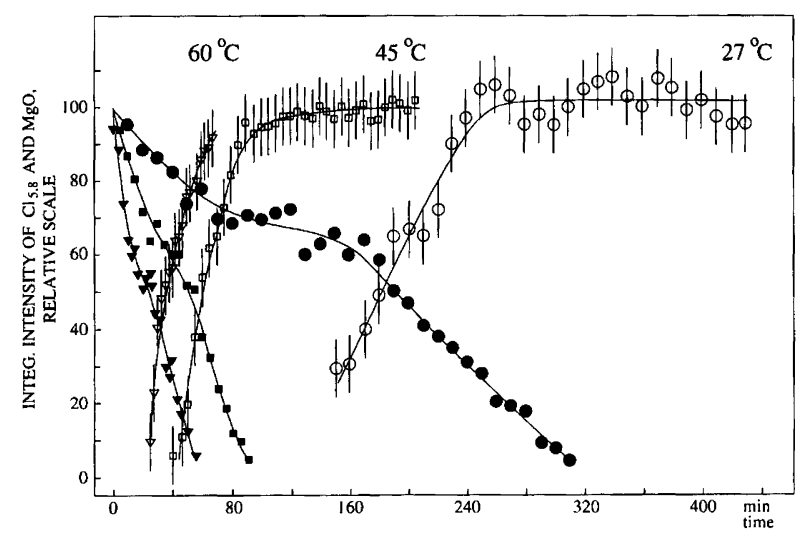

Fig. 7. Integrated intensities of Bragg reflections of $\mathrm{MgO}$ (filled symbols) and $\mathrm{Cl}_{5,8}$ (open symbols) vs. time for the reaction between $\mathrm{MgO}$ and the $4.6 \mathrm{M} \mathrm{MgCl}_{2}$ solution at 27 , 45 and $60^{\circ} \mathrm{C}$, respectively.

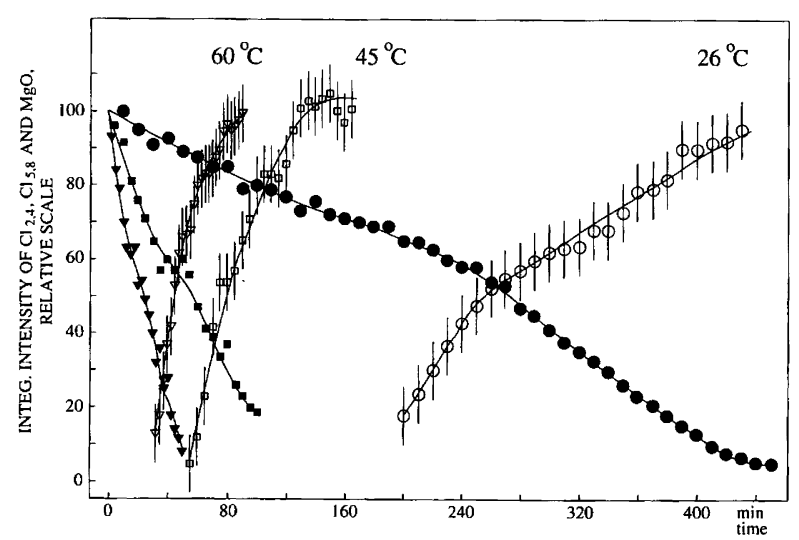

Fig. 8. Integrated intensities of Bragg reflection of $\mathrm{MgO}$ (filled symbols) and $\mathrm{Cl}_{5,8}$ and $\mathrm{Cl}_{2,4}$ (open symbols) vs. time for the reaction between $\mathrm{MgO}$ and the $4.9 \mathrm{M} \mathrm{MgCl}_{2}$ solution at 26 , 45 and $60^{\circ} \mathrm{C}$, respectively. 
Table 2. Rate constants $k$ (in $\min ^{-1}$ ) and $t_{0}$ (in $\mathrm{min}$ ) from the exponential fit of the degree of crystallization using the expression $I=100\left\{1-\exp \left[-k\left(t-t_{0}\right)\right]\right\}$. The values listed for each experiment are $k, t_{0}$.

\begin{tabular}{|c|c|c|c|c|}
\hline \multirow[b]{2}{*}{$T /{ }^{\circ} \mathrm{C}$} & \multicolumn{4}{|c|}{ Concentration of $\mathrm{MgCl}_{2}$ solution/M } \\
\hline & 3.8 & 4.2 & 4.6 & 4.9 \\
\hline $\begin{array}{r}100 \\
80 \\
60 \\
45 \\
26-33\end{array}$ & $\begin{array}{l}0.28,1 \\
0.13,0 \\
0.070,23 \\
0.038,46 \\
0.017,119\end{array}$ & $\begin{array}{l}0.70,2 \\
0.63,4 \\
0.060,21 \\
0.054,42 \\
0.013,103\end{array}$ & $\begin{array}{l}0.75,2 \\
0.067,29^{a} \\
0.049,31 \\
0.041,41 \\
0.021, \quad 141\end{array}$ & $\begin{array}{l}0.87,1 \\
0.15,5 \\
0.052,31 \\
0.032,53 \\
0.0086, \quad 178\end{array}$ \\
\hline
\end{tabular}

${ }^{a}$ This value is most likely in error. The temperature of the sample may have been lower than $80^{\circ} \mathrm{C}$.

slightly dependent on the $\mathrm{MgCl}_{2}$ concentrations (Figs. 57). Only in the case with the $4.9 \mathrm{M} \mathrm{MgCl}_{2}$ solution is the consumption of $\mathrm{MgO}$ significantly slower (Fig. 8). This may be an effect of increasing viscosity of the solutions. The curves showing the consumption of $\mathrm{MgO}$ indicate that the consumption does not proceed with constant rate; this is best observed in Figs. 6-8 for the room-temperature experiments. It is also observed that the consumption of $\mathrm{MgO}$ is significant before the Bragg reflections of the reaction products are observed. This may indicate that the formation of the reaction products goes through an amorphous state for $\mathrm{MgO}$. Figures 5-8 show the formation of the reaction product $\mathrm{Cl}_{5,8}$ to be strongly temperature dependent. The time (in $\mathrm{min}$ ) used to produce half the quantity of the reaction products can be estimated from Figs. 5-8, and these numbers are indicated adjacent to the respective symbols for the experiments in Fig. 2, which also have the corresponding values for the experiments performed at 80 and $100^{\circ} \mathrm{C}$.

The integrated intensity of a selected Bragg reflection of the reaction product is representative for the degree of crystallization of the product. These data for the crystallization curves from the 20 experiments (Fig. 2) were fitted using the exponential expression $I=100\left\{1-\exp \left[-k\left(t-t_{0}\right)\right]\right\} . I$ is the amount of crystalline reaction product, $k$ is the rate constant (in $\min ^{-1}$ ), and $t_{0}$ is the time (in min) at which the crystallization starts. The data gave acceptable fits to this expression. In Table 2 are listed the values obtained for $k$ and $t_{0}$. The results for the experiments with the $4.6 \mathrm{M} \mathrm{MgCl}_{2}$ solution at $80^{\circ} \mathrm{C}$ are most likely in error. The temperature of the sample may have been lower than $80^{\circ} \mathrm{C}$, which also explains why the reaction product obtained was $\mathrm{Cl}_{5,8}$ and not $\mathrm{Cl}_{9,5}$.

Acknowledgements. The Danish Natural Science Research Council has supported this investigation with a grant. The synchrotron X-ray measurements were carried out at Brookhaven National Laboratory, supported under contract DE-AC02-76CH00016 with the US Department of Energy by its Division of Chemical Sciences Office of Basic and Energy Science. The Danish National Agency of Industry and Trade is thanked for a grant covering the cost for the Stoe diffractometer, and Carlsbergfondet is thanked for the differential thermal analysis-thermogravimetric analysis instrument. Mrs. M. A. Chevallier, Mrs. C. Secher, Mr. A. Lindahl and Mr. N. J. Hansen are acknowledged for valuable assistance.

\section{References}

1. Christensen, A. N., Norby, P. and Hanson, J. C. J. Solid State Chem. 114 (1995) 556.

2. Pascal, P. Nouveau Traité de Chimie Minérale, Masson et Cie, Paris 1958, Vol. 4, p. 177.

3. Bianco, Y. Ann. Chim. 13th Ser. 3 (1953) 370.

Received September 12, 1994. 